\title{
Pharmacological management of inappropriate sexual behaviors in youth with autism spectrum disorder: A case study and review of the literature
}

\author{
Traitement médicamenteux de comportements sexuels inappropriés chez les jeunes atteints d'un \\ trouble de l'autisme: un cas clinique et revue de la littérature
}

\author{
F. Chen*, C. Grandjean, S. Richard \\ Département de psychiatrie, service de psychiatrie pour enfants et adolescents (SPEA), secteur psychiatrique Nord (SPN), centre hospitalier universitaire Vaudois
} (CHUV), 12, rue du Valentin, 1400 Yverdon-les-Bains, Switzerland

\begin{abstract}
Inappropriate sexual behaviors are common in children and youth with autism spectrum disorder that could lead to major distress in the patient and caregivers and sometimes could lead to the patient's expulsion from a social environment. When educational and behavioral intervention failed in reducing such behaviors, pharmacological management would be necessary. We presented here a clinical vignette of treatment of inappropriate sexual behaviors in an adolescent boy with autistic disorder. We further made a review of the literature on its pharmacological management. Our review revealed very limited documentation with only some cases studies that have reported successful treatment by several medications. More controlled studies are needed.

(C) 2016 Elsevier Masson SAS. All rights reserved.
\end{abstract}

Keywords: Inappropriate sexual behaviors; Autism spectrum disorder; Pharmacological management

\section{Résumé}

Les comportements sexuels inappropriés sont fréquents chez les jeunes atteints d'un trouble de l'autisme. Ce type de comportement socialement inacceptable peut entraîner des rejets sociaux et des grandes souffrances chez le patient et sa famille. Malgré des mesures éducatives et des interventions comportementales, un traitement médicamenteux est parfois nécessaire pour mieux gérer ce type de comportement. Nous présentons ici un cas clinique et une revue de littérature sur le traitement médicamenteux de comportements sexuels inappropriés chez les jeunes atteints d'un trouble de l'autisme.

(C) 2016 Elsevier Masson SAS. Tous droits réservés.

Mots clés : Comportements sexuels inappropriés; Autisme ; Traitement médicamenteux

\section{Introduction}

Autism spectrum disorder (ASD) is characterized by persistent deficits in social interaction and social communication across multiple contexts, as well as restricted and repetitive patterns of behavior, interests or activities [1]. Despite of the uncommon developmental trajectories, many individuals with

\footnotetext{
* Corresponding author.

E-mail address: fei.chen@chuv.ch (F. Chen).
}

autism demonstrate their interest in discovering sexuality $[2,3]$ and desire relationships, as their peers with a typical development do. It seems important to accept sexuality as a normative part of adolescent development in youth with ASD who may suffer from particular difficulties on learning and daily functioning relating to sexuality [4]. Studies examining children and younger adolescents with ASD demonstrate that they may have less sex education and poorer knowledge regarding privacy issues and display more inappropriate sexual behaviors [2] mostly due to a poorer social ability and lack of effective sexual education. Children with autism may require intensive social and sexual 
education interventions starting at a very young age [5]. However, even pediatricians who were aware of such importance found it difficult to address sexuality-related issues in children and youth with ASD especially topics about prevention of sexual abuse and inappropriate sexual behaviors [6]. Previously reported inappropriate sexual behaviors in children and youth with ASD include undressing or masturbating in public, excessive masturbation, touching other people's private body area and sexual fetishism. One of the primary parental concerns relating to sexuality is the vulnerability of their child with ASD to involvement in sexual risk taking and negative sexual behaviors outcomes (being sexually abused or demonstrating behaviors that can be misregarded as sexually provocative) [7]. To prevent and treat socially unacceptable sexual behaviors, psychoeducation programs and behavior therapy have often been proposed as first-line intervention and have demonstrated their efficacy [8]. When educational and behavioral intervention failed in reducing such target behaviors, pharmacological management would be necessary. To date, however, still little is known about the use of medication to treat inappropriate sexual behaviors in children and young adults, especially in those with ASD.

Here, we presented a clinical vignette of treatment of inappropriate sexual behaviors in a 14-year-old adolescent boy with autistic disorder. We further made a review of the literature to expand our knowledge about pharmacological management of inappropriate sexual behaviors in youth with ASD.

\section{Clinical vignette}

Samuel ${ }^{1}$ is a 14-year-old male adolescent with autism with a normal IQ. The early warning signs of autism have been observed at nursery: he had poor eye contact and attention deficit; he rarely spoke to others or used only echolalia; he seemed to be in his own world and failed to initiate or respond to social interactions with his pairs; he didn't have pretend play. He was then integrated in a special class and benefited a lot from a speech-language therapy. Samuel later acquired a better level of language and showed a preserved cognitive ability. When he was 9 , risperidone (Risperdal ${ }^{\circledR}$ ) $0.5 \mathrm{mg} /$ day was administered to manage his aggression and self-injurious behaviors related to his social-communicating difficulties. These behavioral problems quickly diminished. However, risperidone led to a progressive but important weight gain in spite of dietetic counseling. When he was 12 , risperidone was replaced by aripiprazole $\left(\right.$ Abilify $\left.{ }^{\circledR}\right) 10 \mathrm{mg} /$ day. The weight gain stagnated while Samuel began complaining of persisting tiredness and headache. His parents reported daytime erection and think it could be a side effect of the medication. Aripiprazole was then progressively stopped and replaced later by amisulpride $\left(\operatorname{Solian}{ }^{\circledR}\right)$.

Samuel's hypersexual behaviors appeared about 2 years ago with the onset of puberty. He was once excluded from a sport club after having touched provocatively the breast of a girl in order to show his discontent to the monitor. He was reported to have excessive open masturbation at home, which was very

\footnotetext{
${ }^{1}$ All the identifying details have been changed.
}

embarrassing for other family members. More recently, a teenager girl accused Samuel to have forced her to be touched and suced on her private part in toilet. Samuel seemed to be confused and hurt, asking why the girl who accepted his kiss would accuse him for sexual caress. For him, they were already a couple after the kiss and a couple should have sexual relationship. After this event, Samuel became very anxious and showed depressed mood with suicidal threat. He was hospitalized during 4 weeks in a child and adolescent psychiatric inpatient unit. The daily dose of his treatment by amisulpride was then increased to $300 \mathrm{mg}$. His anxiodepressive symptoms rapidly diminished and he didn't show any inappropriate sexual behavior during the hospitalization. He was now back to school and waiting for an evaluation and guidance on sexuality prescribed by the Juvenile Court. A residential treating center specialized for individuals with autism could be very helpful to offer him psychoeducation programs and behavior therapy on sexuality. Unfortunately, only very limited places exist in the French-speaking part of Switzerland.

In this clinical vignette, the patient presented 3 types of challenging behaviors. The first one seems to be a kind of impulsive provocative behavior with less sexual intention. Samuel explained that he touched the breast of the girl in the swimming pool although he knew it's forbidden. He did it anyway to show that he was angry at the monitor. Undoubtedly, this behavior was perceived by others as with clear sexual intention while it was not the case for Samuel. The second type of inappropriate sexual behaviors is his excessive open masturbations at home which should be nuanced, in our opinion, in the light of normal adolescent sexuality development. Samuel has never been reported to masturbate outside his home; however, it seems to be still difficult for him to understand that "at home" is not equal to "private". The third type of inappropriate sexual behaviors for which he has been accused was with clear sexual intention while based on some romantic feelings. Apparently, Samuel didn't understand that more intimate approach without consent would be perceived as sexual offending. Due to their core social deficits, individuals with ASD may be naive about potential consequences of their social-rule-breaking-behaviors.

\section{Review of the literature}

In order to expand our knowledge about pharmacological management of inappropriate sexual behaviors in children and youth with ASD, we further reviewed related publications via Medline (http://www.ncbi.nlm.nih.gov/pubmed). Only English publications were included, covering children and young adults aged up to 24 years (as defined by United Nations the term "youth"). We have chosen especially reports describing pharmacological agents other than antipsychotics that have been widely used in individuals with ASD.

As shown in Table 1, the literature on pharmacological treatment of inappropriate sexual behaviors in children and youth with ASD seems to be very limited. Medline search revealed only several case reports, including 6 single-case reports [5,9-13] and 1 case-series [14].

Successful suppression of inappropriate sexual behaviours has been reported in a 24-year male with ASD [5], using 
Table 1

Case reports of pharmacological treatment of inappropriate sexual behaviors in youth with ASD.

\begin{tabular}{|c|c|c|c|c|}
\hline Author & Treatment & Subjects (age) & Target symptoms & Effective dosage \\
\hline Realmuto and Ruble (1999) [5] & Leuprolide (injectable) & 1 male, 24 years & $\begin{array}{l}\text { Persistent public } \\
\text { masturbation }\end{array}$ & $\begin{array}{l}7.5 \mathrm{mg} / \mathrm{month} \\
\text { (then switched } \\
\text { slowly to a } \\
\text { maintenance dose } \\
\text { of } 1.87 \mathrm{mg} / \mathrm{month} \text { ) }\end{array}$ \\
\hline Jones and Okere (2008) [9] & Estrogen (oral) & 1 male, 23 years & $\begin{array}{l}\text { Hypersexual behavior, } \\
\text { toward female strangers } \\
\text { with masturbation and } \\
\text { penile discharge }\end{array}$ & $0.625 \mathrm{mg} /$ day \\
\hline Nguyen and Murphy (2001) [10] & Mirtazapine (oral) & 1 male, 13 years & $\begin{array}{l}\text { Excessive masturbation } \\
\text { with public display }\end{array}$ & $45 \mathrm{mg} /$ day \\
\hline Albertini et al. (2006) [11] & Mirtazapine (oral) & 1 male, 5 years & $\begin{array}{l}\text { Compulsive public } \\
\text { masturbation }\end{array}$ & $5 \mathrm{mg} /$ day \\
\hline Coskun and Mukaddes (2008) [12] & Mirtazapine (oral) & 1 male, 13 years & $\begin{array}{l}\text { Fetishism and public } \\
\text { inappropriate sexual } \\
\text { behaviors }\end{array}$ & $15 \mathrm{mg} /$ day \\
\hline Coskun et al. (2009) [14] & Mirtazapine (oral) & $\begin{array}{l}8 \text { males and } \\
1 \text { female aged } \\
5.2-16.4 \text { years }\end{array}$ & $\begin{array}{l}\text { Excessive masturbation, } \\
\text { fetishism and public } \\
\text { inappropriate sexual } \\
\text { behaviors }\end{array}$ & $7.5-30 \mathrm{mg} /$ day \\
\hline Deepmala and Agrawal (2014) [13] & Propranolol (oral) & 1 male, 13 years & $\begin{array}{l}\text { Public display of } \\
\text { inappropriate sexual } \\
\text { behaviors }\end{array}$ & $0.3 \mathrm{mg} / \mathrm{kg} / \mathrm{day}$ \\
\hline
\end{tabular}

injectable leuprolide that could reduce testosterone level by acting as an agonist at pituitary GnRH receptors. While flutamide, an anti-androgen has not been effective in this patient. Oral estrogen has been applied in a 23-year male with ASD [9] leading to a significant reduction in his hypersexual behavior. Albertini et al. [11] reported an effective daily dosage of $5 \mathrm{mg}$ of mirtazapine in treating compulsive public masturbation in a 5-year boy with ASD. Nguyen and Murphy [10] reported beneficial effects of mirtazapine with a daily dose of $45 \mathrm{mg}$ in minimizing hypersexual behaviors in a 13-year boy with ASD, while Coskun and Mukaddes [12] reported a successful suppression of fetishism and public inappropriate sexual behaviors with a daily dose of only $15 \mathrm{mg}$ of mirtazapine in an autistic boy of the same age. Coskun et al. [14] confirmed the efficacy of mirtazapine in treating excessive masturbation, fetishism and public inappropriate sexual behaviors in a case-series of 9 children and adolescents with ASD. A more recent case study [13] reported a low-dose trial of propranolol $(0.3 \mathrm{mg} / \mathrm{kg} /$ day $)$ leading to significant improvement in hypersexual behaviors in a 13-year adolescent with ASD.

\section{General discussion}

Inappropriate sexual behaviors are common in children and youth with ASD who are known to have particular difficulties "on learning and daily functioning relating to sexuality" $[4,15]$. These socially unacceptable behaviors could lead to major distress in the patient and caregivers and sometimes could lead to the patient's expulsion from a social environment [13], as what happened to Samuel in our case presentation. Children and young adults with ASD have the right, and need to learn how, to express their sexual impulses and to manage their sexual needs in a socially acceptable way [16].

When educational and behavioral intervention failed in reducing such behaviors, pharmacological management would be necessary. Our review revealed that the literature on pharmacological treatment of such behaviors especially in children and youth with ASD is very limited. In our opinion, the limited use of pharmacological management of inappropriate sexual behaviors is mainly due to the complex nature of such behaviors in children and youth with ASD who suffer from their disabilities in expressing the desire of relationship, in discovering the sexuality and in establishing a sexual identity. As has been pointed out by Realmuto and Ruble [5], there are still many "unanswered clinical, ethical and legal dilemmas for treatment of sexual deviance in individuals with developmental disability". Although the anti-androgenic medications (leuprolide, flutamide, estrogen, medroxyprogesterone acetate [MPA], cyproterone acetate $\left[\mathrm{CPA}\right.$, Androcur $\left.^{\circledR}\right]$ ) were commonly used in adult sex offenders, one could hardly apply them as firstline choice in younger patients with ASD, for ethical reason. In non-autistic adolescents with and without mental retardation, CPA has been reported to be an efficient treatment of sexually deviant behaviors $[17,18]$. Liver toxicity has been recognized as a complication of long-term use of CPA [19]. Testosterone suppression may also lead to osteoporosis. Caution is especially warranted in children and young adolescents because the effects of hormonal agents on the normal growth and development of youth are not known [20]. The American academy of child and adolescent psychiatry (AACAP) discouraged their use with youth under the age of 17 [21].

Atypical antipsychotics have also been used to treat adult sex offenders since sexual dysfunction is a common side effect in 
patients treated with antipsychotics. However, hyper-sexuality could also appear as side effect of antipsychotics, which has been reported in adults taking aripiprazole [22] and in pediatric patients treated with olanzapine [23]. In individuals with autism, the antipsychotic drugs are among the most commonly used psychopharmacological agents for the treatment of challenging behaviors (aggression toward others, self-injury, etc). It is thus important to evaluate firstly the contribution of actual antipsychotic medication to the target inappropriate sexual behaviors before increasing the dose of the antipsychotics or applying other medication. In our case study, the administration of another atypical antipsychotic successfully helped the patient to better control his impulsive sexual thoughts and behaviors and it has not been necessary to use other more specific medication to treat the target behavior. Samuel's daytime erection was reported coincidentally after the administration of aripiprazole. It has been suggested that antipsychotics causing higher serotonin and less dopamine blockade may have more risk of drug-related hyper-sexuality [23]. Drug-induced hyperprolactinemia has also been hypothesized to be responsible for secondary sexual dysfunctions observed in patients treated by antipsychotic medications. Some second-generation antipsychotics are considered as "prolactin-raising" (especially amisulpride, risperidone and paliperidone which were associated with the highest hyperprolactinemia) while other second-generation antipsychotics are considered as "prolactin-sparing" (especially aripiprazole often associated with decreased prolactin level) or neutral (clozapine, quetiapine) [24]. However, the evidence for an association between prolactin elevation and sexual side effects seems to be still contradictory and inconclusive [24]. In our patient Samuel, unfortunately, the prolactinemia has not been measured. We know only that he didn't develop a gynecomastia but we don't know whether his positive evolution was due to a potential druginduced hyperprolactinemia.

Selective serotonin reuptake inhibitors (SSRIs) have also been used to treat hyper-sexuality not only because inappropriate sexual behaviors are often considered as compulsive in nature but also because serotonin is considered as the main inhibitory neurotransmitter of sexual response [25]. However, SSRIs has been reported to worsen the level of irritability and to have other behavioral side effects including "restless, hyperactivity, excessive activation" leading to discontinuation of the treatment [10]. Mirtazapine is an antidepressant with potent $\alpha 2$-adrenergic antagonism, resulting in an increase of both noradrenergic and serotoninergic neurotransmission [26]. Its reported efficacy in treating inappropriate sexual behaviors seems to be associated to its serotonergic activity [10]. The known side effects of mirtazapine are sedation and weight gain, which should be taken into consideration when making treatment choices in children and adolescents. In our case study, the important overweight of the patient made mirtazapine difficult to be a first-line choice.

Propranolol is a widely-used beta-blocker and "may potentially impact on sexual functioning through a variety of mechanisms, including a reduction in central sympathetic outflow, impairment of vasodilation of the corpora cavernosa, effects on luteinizing hormone and testosterone secretion and a tendency to produce sedation or depression, thereby causing a loss of libido" [27]. It's a FDA approved treatment for children with hypertension and arrhythmia and is considered safe and generally well tolerated in children. The above-mentioned successful low-dose propranolol trial for minimizing hypersexual behavior in an adolescent with ASD [13] offers a new therapeutic option.

\section{Conclusion}

Inappropriate sexual behaviors are common challenging behaviors in children and youth with autism. Psychoeducation programs and behavior therapy have demonstrated their efficacy. Specialized institution is needed in order to promote these programs. The anti-androgenic medications are not recommended as first-line choice in pediatric population and caution is especially warranted because of their unknown effect on the children's growth and development. Some atypical antipsychotics could also be used to treat these socially unacceptable behaviors when educational and behavioral intervention failed in reducing them. Mirtazapine and propranolol provide interesting therapeutic option, but the literature is still very limited. More controlled studies are needed.

\section{Disclosure of interest}

The authors declare that they have no competing interest.

\section{References}

[1] American psychiatric association. Diagnostic and statistical manual of mental disorders. 5th ed. Arlington, VA: American psychiatric association; 2013.

[2] Stokes MA, Kaur A. High-functioning autism and sexuality. Autism 2005;9(3):266-89.

[3] Tissot C. Establishing a sexual identity, case studies of learners with autism and learning difficulties. Autism 2009;13(6):551-66.

[4] Dewinter J, Vermeiren R, Vanwesenbeeck I, Lobbestael J, Van Nieuwenhuizen C. Sexuality in adolescent boys with autism spectrum disorder: self-reported behaviours and attitudes. J Autism Dev Disord 2015;45(3):731-41

[5] Realmuto GM, Ruble LA. Sexual behaviors in autism: problems of definition and management. J Autism Dev Disord 1999;29(2):121-7.

[6] Holmes LG, Himle MB, Sewell KK, Carbone PS, Strassberg DS, Murphy NA. Addressing sexuality in youth with autism spectrum disorders: current pediatric practices and barriers. J Dev Behav Pediatr 2014;35(3): $172-8$.

[7] Ballan MS. Parental perspectives of communication about sexuality in families of children with autism spectrum disorders. J Autism Dev Disord 2012;42:676-84.

[8] Early MC, Erickson CA, Wink LK, McDougle CJ, Scott EL. Case report: 16-year-old male with autistic disorder with preoccupation with female feet. J Autism Dev Disord 2012;42:1133-7.

[9] Jones MC, Okere K. Treatment of hypersexual behavior with oral estrogen in an autistic male. South Med J 2008;101(9):959-60.

[10] Nguyen M, Murphy T. Mirtazapine for excessive masturbation in an adolescent with autism. J Am Acad Child Adolesc Psychiatry 2001;40(8):868-9.

[11] Albertini G, Polito E, Sarà M, Di Gennaro G, Onorati P. Compulsive masturbation in infantile autism treated by mirtazapine. Pediatr Neurol 2006;34(5):417-8.

[12] Coskun M, Mukaddes NM. Mirtazapine treatment in a subject with autistic disorder and fetishism. J Child Adolesc Psychopharmacol 2008;18(2):206-9. 
[13] Deepmala, Agrawal M. Use of propranolol for hypersexual behavior in an adolescent with autism. Ann Pharmacother 2014;48(10):1385-8.

[14] Coskun M, Karakoc S, Kircelli F, Mukaddes NM. Effectiveness of mirtazapine in the treatment of inappropriate sexual behaviors in individuals with autistic disorder. J Child Adolesc Psychopharmacol 2009;19(2):203-6.

[15] Beddows N, Brooks R. Inappropriate sexual behaviors in adolescents with autism spectrum disorder: what education is recommended and why. Early intervention in Psychiatry 2015 [in press].

[16] Hellemans $\mathrm{H}$, et al. Sexual behavior in high-functioning male adolescents and young adults with autism spectrum disorder. J Autism Dev Disord 2007;37(2):260-9.

[17] Bradford JMW. The pharmacological treatment of the adolescent sex offender. In: Barbaree HE, Marshal WL, Hudson SM, editors. The juvenile sex offender. New York: Guilford press; 1993. p. 278-88.

[18] Davies TS. Cyproterone acetate for male hypersexuality. J Int Med Res 1974;2:159-63.

[19] Garty BZ, Dinari G, Gellvan A, Kauli R. Cirrhosis in a child with hypothalamic syndrome and central precocious puberty treated with cyproterone acetate. Eur J Pediatr 1999;158:367-70.

[20] Thibaut F, et al. The World federation of societies of biological psychiatry (WFSBP) guidances for the treatment of adolescent sexual offenders with paraphilic disorders. World J Biol Psychiatry 2016;17(1):2-38.
[21] Shaw JA, American academy of child and adolescent psychiatry working group on quality issues. Practice parameters for the assessment and treatment of children and adolescents who are sexually abusive of others. J Am Acad Child Adolesc Psychiatry 1999;38:55-76.

[22] Cheon EJ, Koo BH, Seo SS, Lee JY. Two cases of hyper-sexuality probably associated with aripiprazole. Psychiatry Investig 2013;10: 200-2.

[23] Herguner S. Excessive masturbation associated with olanzapine in a pediatric case. Prog Neuropsychopharmacol Biol Psychiatry 2010;34: 1349-50.

[24] Peuskens J, Pani L, Detraux J, De Hert M. The effects of novel and newly approved antipsychotics on serum prolactin levels: a comprehensive review. CNS Drugs 2014;28:421-53.

[25] Werneke U, Northey S, Bhugra D. Antidepressants and sexual dysfunction. Acta Psychiatr Scand 2006;114:384-97.

[26] Stimmel GL, Dopheide JA, Stahl SM. Mirtazapine: an antidepressant with noradrenergic and specific serotonergic effects. Pharmacotherapy 1997;17(1):10-21.

[27] La Torre A, Giupponi G, Duffy D, Conca A, Catanzariti D. Sexual dysfunction related to drugs: a critical review. Part IV: cardiovascular drugs. Pharmacopsychiatry 2015;48:1-6. 